\title{
Effect of Particle Size and Concentration of Fly Ash on Properties of Polytrimethylene Terepthalate
}

\author{
Vivek.R.Gaval ${ }^{1}$, R.S.N.Sahai ${ }^{2}$ \\ ${ }^{1}$ Associate professor,Department of General Engineering, Institute of Chemical Technology, Matunga, \\ Mumbai, 4000019, India. \\ ${ }^{2}$ Assistant professor,Department of General Engineering, Institute of Chemical Technology, Matunga, \\ Mumbai, 4000019, India.
}

\begin{abstract}
Particle filled polymer composites have become attractive because of their wide applications and low cost. Incorporating inorganic mineral fillers into plastic resin improves various physical properties of the materials such as mechanical strength, modulus and heat distortion temperature. In general the mechanical properties of particulate filled polymer composites depend strongly on size, shape and distribution of filler particles in the matrix polymer and good adhesion at the interface surface. In this study, the effect of the fly ash with different particle size and different filler concentration (5 to 20\% by weight) on the mechanical, electrical and thermal properties of the polytrimethylene terepthalate (PTT) was investigated.

The PTT Composites of fly ash were prepared by Haake Rheocord 9000 machine. The standard test specimens were molded on Injection moulding machine. Mechanical and electrical properties were determined using these test specimens. It was found that with the addition of fly ash as a filler in PTT showed improvement in Mechanical properties such as Elastic modulus, stiffness and hardness with the increase in fly ash concentration., whereas tensile strength and elongation at break values are found to decrease with increase in fly ash concentration. .Dielectric strength was found to be increased with the fly ash concentration.. Morphological studies revealed that there is a good dispersion and wetting of the fly ash with PTT matrix.
\end{abstract}

Keywords: Polytrimethylene terepthalate (PTT), Fly ash, Mechanical, Thermal Electrical Properties and Scanning Electron Microscope(SEM)

\section{Introduction}

Particulate -filled polymer composites are most widely used composite materials than fibrous or any other filled materials. Property improvement in composites is found to be very much dependent on filler size and filler content. Micro and nano sized materials are found to influence the material properties more efficiently compared to fibrous reinforcement.[1-3].In general the Mechanical properties of particulate filled polymer composites depend strongly on size, shape and distribution of filler particles in the polymer matrix and extent of interfacial adhesion between filler and matrix.[4]

Polytrimethylene Terephthalate (PTT) is a semicrystalline polymer that has many of the same advantages as its polyester cousins, PBT and PET. Compared to PBT, compounds composed of PTT exhibit better tensile strengths, flexural strengths, and stiffness. They also have excellent flow and surface finish. PTT can also be more cost effective than PBT. Due to its chemical structure, PTT may have more uniform shrinkage and better dimensional stability in some applications than competing semicrystalline materials[5].

Fly ash had been one of the widely studied filler due to its unique set of properties.[6, 7] In this investigation we studied the effect of fly ash with three varying particle sizes and concentration on the properties of PTT. Recently many investigators studied the effect of fly ash on the properties of thermoplastics and thermosets [815]. Fly ash is the finely divided mineral residue resulting from the burning of pulverised coal in thermal power stations. Fly ash has been used in industry because of such advantages as low density, low cost, strong filling ability, smooth spherical surface, small and well distributed internal stress in the products and good processability of the filled materials. Fly ash provides cost effective improvements in the critical properties for a wide range of polymer composites. Polyester thermoplastic elastomer composites. 


\section{Experimental}

\subsection{Materials Used}

The matrix polytrimetylene Terepthalate with $1.19 \mathrm{~g} / \mathrm{cc}$ density was procured from Shell chemicals,Canada. The filler flyash of three different particle sizes $(25-40 \mu \mathrm{m}, 90-105 \mu \mathrm{m} \& 180-200 \mu \mathrm{m})$ was obtained from Pozocrete Minerals (Mumbai, India). The detail list of materials used is given in Table 1 below.

\subsection{Compounding}

Polytrimethylene terepthalate (PTT), and Fly ash were pre dried at $105^{\circ} \mathrm{C}$ for 4 to 5 hours in an air circulating oven. In binary systems, the compounding of Polytrimethylene terepthalate (PTT) with various concentrations of $0,5,10,15,20$ weight percent (wt \%) of the Fly ash were carried out by using counter rotating twin screw extruder Haake Rheocord 9000 with a screw of $16 \mathrm{~mm}$ diameter and L/D ratio of 25:1.The extrudate was quenched in water at a temperature of about $20-30^{\circ} \mathrm{C}$. For the melt blending the temperature profile of the extrusion were as follows, Zone 1: $\left(210^{\circ} \mathrm{C}\right)$, Zone $2:\left(220^{\circ} \mathrm{C}\right)$, Zone $3:\left(235^{\circ} \mathrm{C}\right)$ and Die $\left(245^{\circ} \mathrm{C}\right)$. The extrudates were pelletised in Boolani's pelletizing machine. The speed of the pelletizer was maintained between the range of 2-3 rpm.

\subsection{Injection Molding}

The granules of the extrudates were predried in an air circulated oven at $85-90^{\circ} \mathrm{C}$ for $3-4$ hours and then injection molded in a family mold cavity using microprocessor based injection moulding machine (ENGEL 920,Austria ) fitted with a master mould containing the cavity for tensile strength, flexural and impact specimens. After its ejection from the mould, specimens were cooled. Processing parameters are Zone 1: (230 $\left.{ }^{\circ} \mathrm{C}\right)$, Zone 2: $\left(245^{\circ} \mathrm{C}\right)$, Zone 3: $\left(255^{\circ} \mathrm{C}\right)$.

\section{Characterization}

\subsection{Mechanical Properties.}

Tensile strength as per ASTM D638 M91 was evaluated using Universal Testing Machine LR50K from Lloyd instruments Ltd.,U.K at a crosshead speed of $50 \mathrm{~mm} / \mathrm{min}$. Flexural properties according to ASTM D790 M92 were tested using LR 50K from Lloyd instruments Ltd., U.K. Jaw speed of $2.8 \mathrm{~mm} / \mathrm{min}$ was maintained for three point flexural strength and the span was $200 \mathrm{~mm}$. All the reported values are average of at least five samples. Izod impact test were carried out using an Avery Denison pendulum type, impact strength tester (model 6709) with a $2.7 \mathrm{~J}$ striker.The results reported are the average values of at least five specimens.For izod impact test specimens the notch was cut using a motorised notch cutting machine.(Rayran U.K )

\subsection{Electrical Properties}

The Dielectric Strength, according to ASTM D 149, was measured using Zaran Instruments (India) with a 2 $\mathrm{mm}$ thick composite disc. The voltage was increased slowly and the voltage at which the current penetrated the sample was noted. The configurations of the instruments were: input: $240 \mathrm{~V}, 50 \mathrm{~Hz}, 1 \mathrm{PH}$; output: 0-50 kV; capacity: $100 \mathrm{~mA}$; rating: $15 \mathrm{~min}$.

\subsection{Optical Properties.}

The whiteness index, yellowness index, spectral reflectance values of virgin PTT and the composites were measured using a Reflectance Spectrophotometer (Colour Eye 7000A, Gretag-Macbeth). The instrument is based on advanced Multi-Flux theory software). Whiteness and yellowness index of the virgin PTT and composite samples were determined using standard methods. The whiteness index was determined using CIE Ganz 82 method and the yellowness index was determined using ASTM-D1925 method.

\subsection{Morphological Properties}

SEM was used to study morphology of the mica PTT composites.SEM studies of tensile test fractured and liquid nitrogen fractured samples were carried out using JSM-6380LA analytical scanning microscope of Joel make ,Japan. The digitized images of the samples were recorded and studied. 


\section{Results and Discussions}

\subsection{Tensile Properties}

Fig. 1 shows the variation of tensile strength as a function of fly ash in wt $\%$. Tensile strength of composites was found to be decreasing with the addition of filler. The rate of decrease of tensile strength is higher in the case of larger particle size of fly ash. It is observed that fly ash with smaller particles showed higher value of tensile strength. The percentage elongation at break also decreases [10] on addition on filler as shown in Fig. 2. This is due to the interference of filler in the mobility or deformability of the matrix. This interference is created through the physical interaction and immobilisation of the polymer matrix by the presence of mechanical restraints, there by reducing the elongation at break. Fly ash with smaller particle size show higher values of elongation at break.

\section{Tensile Strength Values of Flyash filled PTT Composites}

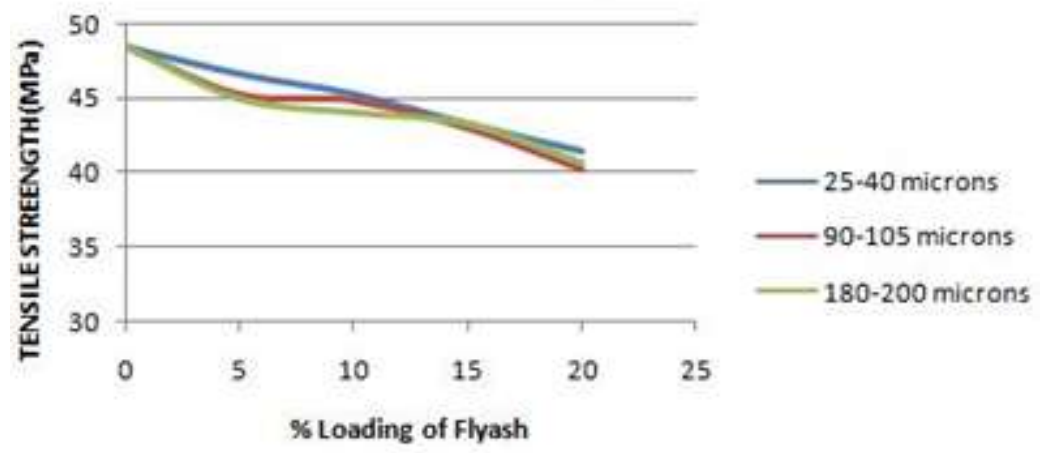

Fig. 1: Variation of Tensile Strength with Filler Loading

\section{\%Elongation at break Values of Flyash filled PTT Composites}

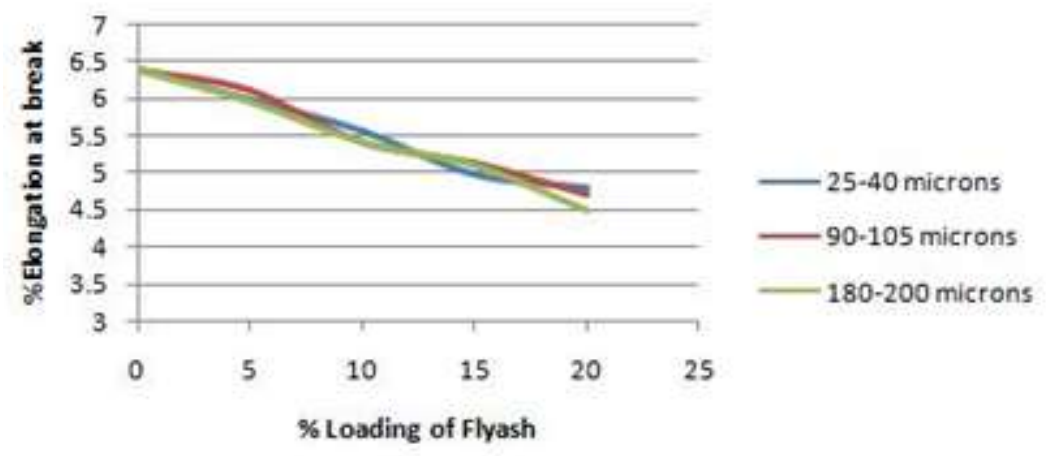

Fig. 2: Variation of \% Elongation at break with Filler Loading.

\subsection{Flexural Properties}

The variation of flexural strength with filler addition is shown in Fig. 3. The flexural strength of composites increases with increase in concentration of fly ash. Composites with fly ash at smaller particle size show higher value of flexural strength. The increment in flexural strength is due to the better increased surface area of filler in the matrix. It is worth pointing out that the total area for deformation stress also has an important role to play. Flexural modulus as shown in Fig.4 is found to increase with increase in concentration of fly ash. The rate of increase of flexural modulus is higher in the case of smaller particle size of fly ash. Composites with fly ash at smaller particle size show consistant and better values of flexural properties. 


\section{Flexural Strength Values of Flyash filled PTT Composites}

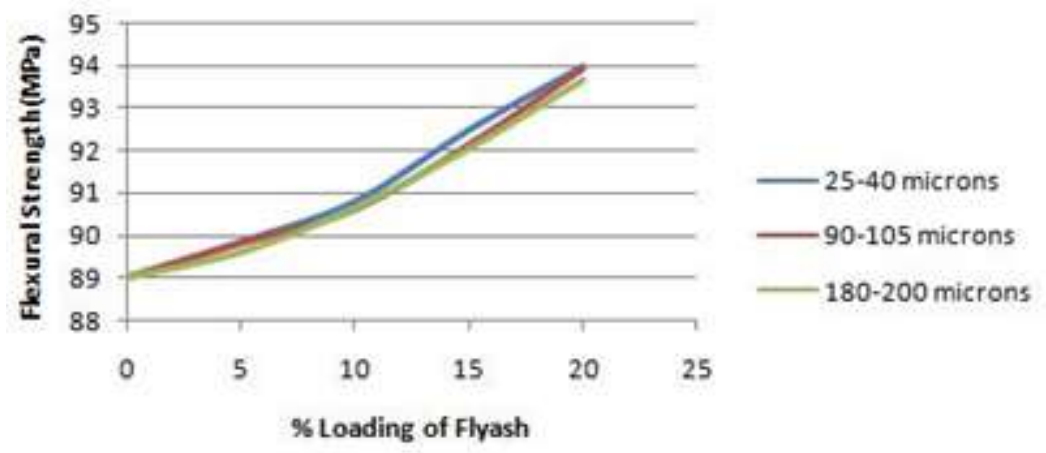

Fig. 3 : Variation in Flexural Strength with Filler Loading.

\section{Flexural modulus Values of Flyash filled PTT Composites.}

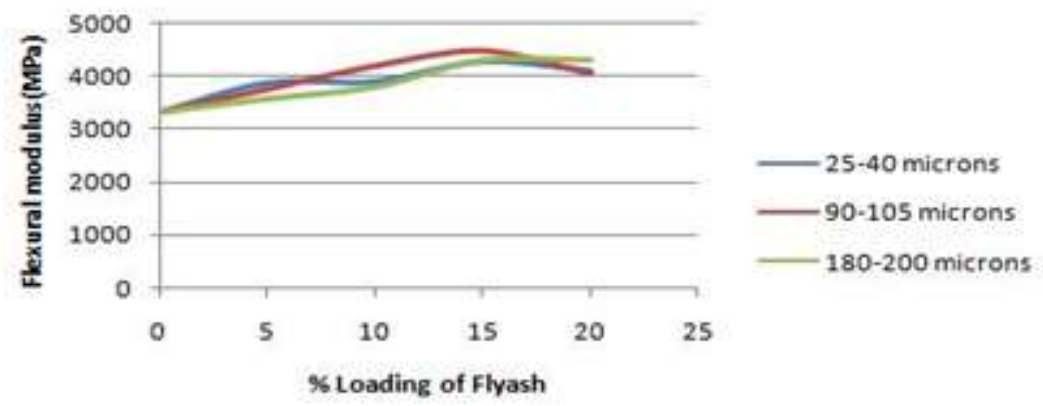

Fig. 4 : Variation in Flexural Modulus with Filler Loading

\subsection{Impact Strength.}

Fig. 5 illustrates the variation of impact strength with filler loading. It is clear from the figure that the impact strength decreases with filler addition. This is mainly due to the reduction of elasticity [4] of material due to filler addition and there by reducing the deformability of matrix .An increase in concentration of filler reduces the ability of matrix to absorb energy and there by reducing the toughness, so impact strength decreases. It is observed that the fly ash with smaller particle size showing higher increment of impact strength. The rate of decrease of impact strength is higher in the case of smaller particle size of fly ash.

\section{Impact Strength Values of Flyash filled PTT Composites}

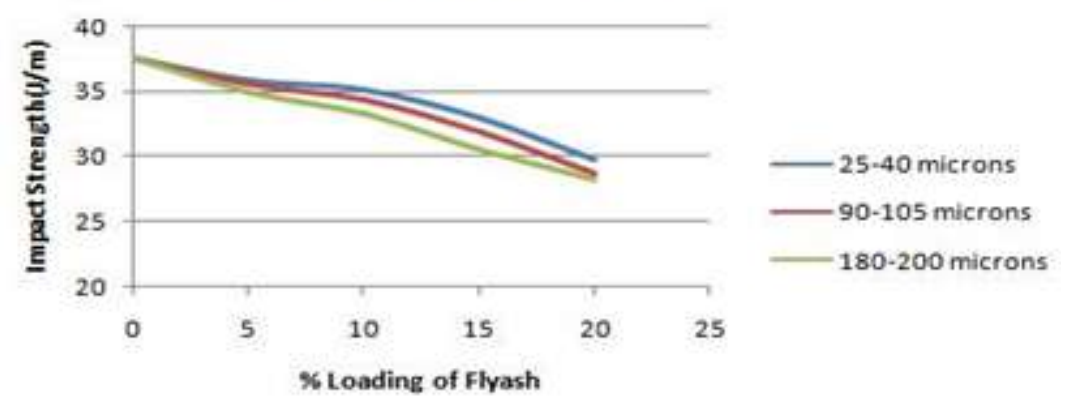

Fig. 5 : Variation in Impact Strength with Filler Loading 


\subsection{Dielectric Strength}

It is clear from Fig. 6 that the dielectric strength increased with the increase in filler concentration and attained maxima. At higher filler loading the dielectric strength values remained almost constant with the increase in filler. This trend in variation of dielectric strength in fly ash is attributed to the total surface area available from the filler as well as its continuity. The dielectric strength is higher for smaller particle size of fly ash.

\section{Dielectric Strength Values of Flyash filled PTT Composites}

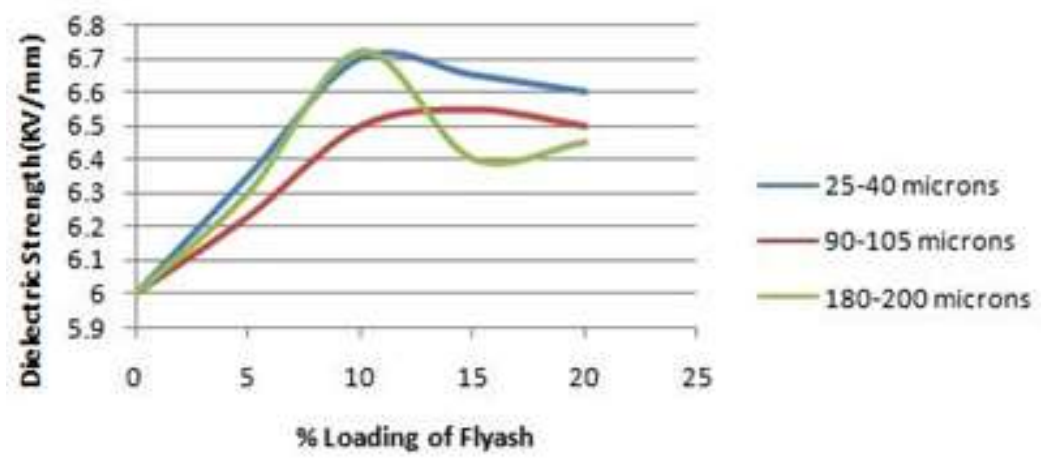

Fig. 6: Variation in Dielectric Strength with Filler Loading

\subsection{Morphological Properties}

SEM is used to study the morphology of composites. Fig.7 shows the SEM micrographs of composites with $20 \%$ loadings of fly ash. Morphological study shows that fly ash having smooth spherical surface having more surface area for interaction. There is a good dispersion of filler particle in the polymer matrix. The interaction between the filler and the matrix is also good as shown in the SEM micrograph.

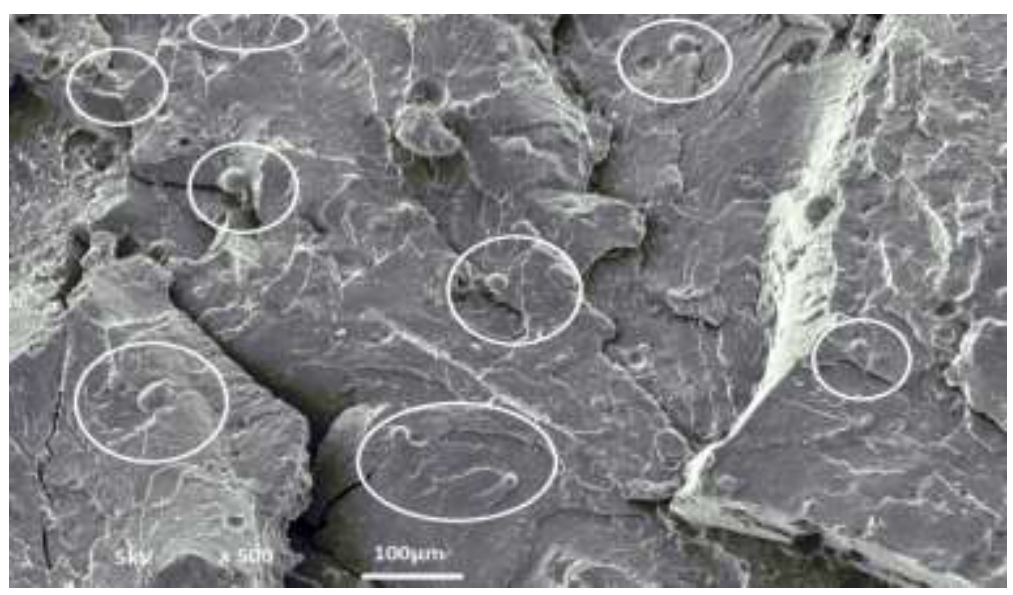

Fig. 7: SEM micrograph of Polytri methylene terepthalate with $10 \%$ Flyash of $25-40 \mu \mathrm{m}$ particle size

\section{Conclusion}

Inorganic fillers viz. fly ash added to the polymer improved its Flexural strength,Flexural modulus but dramatically decreased the tensile strength and elongation at break. There is a significant increment in the flexural strength and modulus with an increase in the filler concentration. The impact strength decreases with concentration of filler due to the reduction of elasticity of material due to filler addition and there by reducing the deformability of matrix. There is a significant increase in the dielectric strength with filler addition. Morphological studies showed that there is a better dispersion of filler in the matrix. The mechanical properties of the composite were found to be a function of the particle size, aspect ratio, the dispersion, the particle 
orientation, the interfacial interaction between the minerals and the polymer matrix. Spherical shaped filler, such as fly ash gave significant improvement in stiffness due to better surface area for interaction. It is concluded that composites with fly ash at smaller particle size showed significant improvement in the overall (mechanical and electrical) properties of composites.

\section{References}

[1] Tung,C.M. and Dynes, P. J. (2003). Morphological Characterization of Poly(etheretherketone)/Carbon Fibre Composites, J. Appl. Polym. Sci., 23(2): 502-520.

[2] Naganuma, T. and Kagawa, Y. (2002). Effect of Particle Size on the Optically Transparent Nano Meter-Order Glass Particle-Dispersed Epoxy Matrix Composites, Compos. Sci. Technol., 62(9): 1187-1189. http://dx.doi.org/10.1016/S0266-3538(02)00059-3

[3] Singh, R.P., Zhang, M. and Chan, D. (2002). Toughening of a Brittle Thermosetting Polymer: Effects of Reinforced Particle Size and Volume Fraction, J.Mater.Sci.,37(4):781-788. http://dx.doi.org/10.1023/A:1013844015493

[4] M.S. Sreekanth , V.A. Bambole, S.T. Mhaske, P.A. Mahanwar.,"Effect of Particle Size and Concentration of Fly ash on Thermoplastic Elastomer Composites.”,J.Min Mat.Char. \& Engg,Vol 8, No 3, pp. 237-248,(2009)

[5] Fiber Industries,Inc.Br.Patent 1254826,1971.

[6] Katz,H.S; J.V Milevski, 1978, "Handbook of Fillers and Reinforcements for Plastics", Vol.1, ed.1, pp. 301-316, New York, Van Notrand Reinhold.

[7] George, W., 1999, Flyash, Mica, Handbook of Fillers, Vol. 1, ed. 2, pp. 32, Toronto, New York, Chem Tech Publishing.

[8] Iftekhar Ahmad and Prakash.A.Mahanawar.," Mechanical Properties of Fly ash Filled High Density Polyethylene.”, J.Min Mat.Char. \& Engg,Vol 9, No 3, pp. 183-198 (2010)

[9] Bose,S., Mahanwar,P.A., 2004, "Effect of flyash on the mechanical, thermal, dielectric, rheological and morphological properties of filled nylon-6" J.Min Mat .Char.\& Engg, Vol. 3, No.1, pp. 23-31. http://dx.doi.org/10.4236/jmmce.2004.32007

[10] Patel. Arunendra Kumar, Bajpai. R,Keller.J.M, Kumari Bindu, Vatsal. V, Saha.A. "Structural, Morphological and Micromechanical Studies on Fly ash Reinforced PMMA Composites.” Microsystem Technologies, Vol.17, No 12, pp 1755-1762.(2011) http://dx.doi.org/10.1007/s00542-011-1356-1

[11] M. Rahul Parvaiz, P.A.Mahanawar, Smita Mohanty, Sanjay.R.Nayak.”Effect of Surface Modification of Fly ash Reinforced in Polyetherether Ketone Composites.” Polymer Composites, Vol.32, Issue 7, pp 1115-1124, July 2011. http://dx.doi.org/10.1002/pc.21129

[12] Menon.A.R.R, Sonia.T.A, 2006, "Studies on Fly-Ash-Filled Natural Rubber Modified with Cardanol Derivatives", $J$ Appl. Polym. Sci., Vol. 102, pp.4801-4808. http://dx.doi.org/10.1002/app.24439

[13] Soyama.M, Inoue.K, 2007, "Flame retardancy of polycarbonate enhanced by adding fly ash" Polym. Adv. Tech. Vol. 18, pp. 386-391. http://dx.doi.org/10.1002/pat.900

[14] Fen.Y.Y, Sheng.G.G, 2006, "Surface modification of purified fly ash and application in polymer", J. Hazard. Mater., vol. 133 pp. $276-282$ http://dx.doi.org/10.1016/j.jhazmat.2005.10.028

[15] Dilip C.D.Nath, Sri Bandopadhya, John Rider, Aibing Yu, Darryl Blackburn and Chris White."Study of Dynamic Mechanical Properties and Morphological Behaviours of Fly ash Reinforced Polypropylene Composites." Macromolecular Research, Vol. 19, No 4, pp 338-344., (2011) http://dx.doi.org/10.1007/s13233-011-0408-9 